\title{
Management of senile atopic dermatitis in geriatric outpatient clinic Dermatovenereology Department Cipto Mangunkusumo Hospital in 2011-2015
}

\author{
Marsha Bianti* \\ Department of Dermatology and Venereology Faculty of Medicine Universitas Indonesia
}

\begin{abstract}
Context: Senile atopic dermatitis is atopic dermatitis (AD) which persists until elderly or the onset first occur in elderly. Though it is relatively uncommon, the number of patients are gradually increasing in industrialized countries associated with aging society.

Aims: The prevalence of senile AD remains unclear and in Indonesia, there have not been any study regarding senile AD yet. Until now, there is no life-long cure for AD. Management comprises of treatment to protect the skin barrier, anti-inflammatory, and the identification and avoidance of trigger factors.

Settings and design: This descriptive study was conducted in Cipto Mangunkusumo Hospital.

Methods and material: This is a descriptive study, using secondary data obtained from Cipto Mangunkusumo Hospital medical record.

Statistical analysis used: None

Results: There were 54 patients with senile AD enrolled in five year period. Females were greater in number than males (59.3\%). Most patients were in 60-69 years old group (63\%) and 31 of 54 patients were unemployed or already retired (57.4\%). Forty subjects were diagnosed with comorbidities and $31.5 \%$ subjects have history of atopy or allergy. The most common type of onset was senile onset, which found in 45 patients (83.3\%). Based on severity, most cases (58\%) were classified as moderate senile $\mathrm{AD}$ and treated with intermittent use of mid-potency topical corticosteroid, as well as regular application of emollient.
\end{abstract}

Conclusions: On observation, the amount of senile AD cases are increasing along with the increasing number of geriatric population and it is should not be underestimated. Proper management of senile AD may improve patients' quality of life.

Key Messages: The number of disease related to geriatric population is increasing every year and AD should not be underestimated. The successful management of $\mathrm{AD}$ requires a combination of treatments and should be tailored. The result of this study can be used to improve the management of $\mathrm{AD}$.

\section{Introduction}

Senile atopic dermatitis $(\mathrm{AD})$ is a chronic relapsing skin disorder, which manifests as dry skin, itching, and various forms of eczematous inflammation which persists until elderly or with first onset on elderly [1]. The number of cases are relatively small thus the prevalence data of senile $\mathrm{AD}$ remains limited until now. However this number is increasing in industrialized countries [2,3]. One study shows that the prevalence of $\mathrm{AD}$ in adult and elderly is 1 to $3 \%$ [4]. In other study, the prevalence of $\mathrm{AD}$ in $>50$ years old patients is 1.5 to $10 \%$ [5]. However, in Indonesia, the prevalence of senile AD is not available yet.

In elderly, diagnosis and treatment of skin related diseases become a challenge to physicians as well as dermatologists because clinical manifestations may become not typical due to aging skin. Moreover, geriatric patients tend to have several health problems, altered body organ functions, and history of previous medications, which make diagnosing and treating skin-related diseases even more complicated. Therefore, it is needed to conduct a study regarding this topic in geriatric outpatient clinic Dermatovenereology Department Cipto Mangunkusumo Hospital in 2011-2015 to know the prevalence and patients' profile as well as the treatment of choice.

\section{Subjects and Methods}

This is a descriptive study, using secondary data obtained from Cipto Mangunkusumo Hospital medical record. Data was taken from February 2016 until all was obtained. All patients with senile AD who came to geriatric outpatient clinic dermatovenereology department Cipto Mangunkusumo Hospital during 2011-2015 were chosen as subjects.

The inclusion criteria are male and female $\geq 60$ years old and clinically diagnosed as senile AD patients. Those below 60 years old and with inactive medical record were exclude from this study.

The obtained data is then processed, analyzed, and critically appraised without statistical tests using IBM SPSS Statistic v.21. The

${ }^{\star}$ Correspondence to: Marsha Bianti, Department of Dermatology and Venereology Faculty of Medicine Universitas Indonesia, dr.Cipto Mangunkusumo National General Hospital, Jakarta, Indonesia, E-mail: marsha. bianti@gmail.com

Key words: geriatric, profile, senile atopic dermatitis, treatment

Received: October 10, 2018; Accepted: October 20, 2018; Published: October 25, 2018 
data is described as socio-demography data which consist of year of visit, sex, age group, occupation, comorbidity, and history of atopy/ allergy. Data is also described as special characteristics, such as type of onset, severity, and treatment. Data is presented in tables and diagrams form with narrative description.

\section{Results}

There were 54 cases of senile $\mathrm{AD}$ in geriatric outpatient clinic Dermatovenereology Department Cipto Mangunkusumo Hospital during 2011-2015. Table 4.1 describes sociodemographic characteristic of subjects.

Thirty two of the 54 subjects (59.3\%) are female and the rest, $40.7 \%$, are male. Most patients belong in age group 60-69 years old $(\mathrm{N}=34$, $63 \%$ ). Thirty one of 54 subjects are unemployed or already retired, 19 subjects are still doing domestic work as housewives, and only four still have active occupation.

Forty subjects were also diagnosed with comorbidities. Seventeen of the fifty four subjects (31.5\%) have history of atopy or allergy, while the rest, 37 subjects (68.5\%), don't have it. However, the history of previous treatment for those who have history of atopy is unclear.

Senile AD is classified into three groups based on the type of onset, which is senile onset, recurrent or continuation from adult $\mathrm{AD}$, and recurrent with classical $\mathrm{AD}$ in childhood. In this study, majority of the cases were senile onset $\mathrm{AD}(\mathrm{N}=45,83.3 \%)$. Eight cases $(14.8 \%)$ were continuation from adult $\mathrm{AD}$ and only one case (1.9\%) was a recurrent case with history of classic $\mathrm{AD}$ in childhood. A pie diagram showing senile AD type of onset percentage is shown in Figure 1.

Based on severity, as shown in Figure 2, most cases (58\%) were classified as moderate senile $\mathrm{AD}$ and treated with intermittent use of mid-potency topical corticosteroid, as well as regular application of emollient. Figure 3 show treatment of choice based on senile AD severity.

\section{Discussion}

All patients aged 60 years and older who came to geriatric outpatient clinic Dermatovenereology Department Cipto Mangunkusumo Hospital and diagnosed with atopic dermatitis become the subject of this study. Most of them came with itch as the chief complaint. There were fifty four patients in five years period, from January 2011 to December 2015. The most number of cases was recorded in 2012, as many as 20 cases (37\%) and more than half of the total subjects belong to the age group 60-69 years old $(\mathrm{N}=34,63 \%)$.

From the results, the number of female patients is more than male patients with almost 3:2 ratio. This result is different from Tanei [6], which most senile AD patients found are male with 3:1 ratio to female. In other studies conducted in Japan, a male predominance was also found [7]. In contrast, several studies of adult AD have indicated that the prevalence in women is higher than men $[8,9]$. It is concluded that gender difference in the prevalence of senile $\mathrm{AD}$ is uncertain, our result probably because in Indonesia, the number of female elderly is higher than male [10].

Senile AD often coexists with other medical conditions, such as hypertension, gastrointestinal disorders, cardiac/cerebral vascular diseases, and diabetes mellitus [6]. This also shown in our study, with $74.1 \%$ of patients have comorbidities. Comorbidities may complicate the diagnosis of $\mathrm{AD}$ since itching and pruritic skin disorders may be due to other disorders and/or side effects of medications.

The clinical findings of senile AD are basically similar to those in adult $\mathrm{AD}$, except localized lichenification in the folds of the elbows and knees [1]. Variable and uncommon clinical findings of senile AD maybe due to individual differences in immune function, epithelial barrier function and environmental factors among elderly people associated with aging [6]. In contrast to infantile or childhood $\mathrm{AD}$, only 17 (31.5\%) of the 54 subjects have history of atopy or allergy on him/ herself or on the family.

Senile $\mathrm{AD}$ is classified into three groups based on the type of onset, which is senile onset, recurrent or continuation from adult $A D$, and recurrent with classical $\mathrm{AD}$ in childhood. In this study, majority of the cases were senile onset $\mathrm{AD}(\mathrm{N}=45,83.3 \%)$. Eight cases (14.8\%) were continuation from adult $\mathrm{AD}$ and only one case (1.9\%) was a recurrent case with history of classic $\mathrm{AD}$ in childhood. The recurrence rate of $\mathrm{AD}$ in the senile phase in patients with history of childhood $\mathrm{AD}$ is still unknown. One study from Sweden shows that $\mathrm{AD}$ persisted in 59 to $68 \%$ patients who had history of adult $\mathrm{AD}$, however this was noted after 25 to 41 years of follow up [8].

Up until now, there is no $100 \%$ life-long cure for AD [6]. Regardless of age, the successful approach to the management of $\mathrm{AD}$ requires a combination of interventions and treatments. A tailor-made medicine for $\mathrm{AD}$ is needed to treat each patients with different conditions, especially the elderly. The treatment aim to identify and eliminate triggering factors, protect and improve the skin barrier, as well as antiinflammatory measurements $[1,6]$.

Intermittent use of topical corticosteroid, along with regular application of moisturizers and emollients, have been the standard management of the disease. Similar to our study, in mild to moderate cases of senile $\mathrm{AD}$, the treatment comprises of emollient and topical corticosteroids. Antihistamines were also used as the first choice in oral therapy. It can inhibit release of chemical mediators and the sedative effects could also effective for intense itching that cause sleep disturbance [6].

In elderly, avoidance of environmental triggering factors is often considered difficult. Moreover, because of their decreased activity daily living with aging and lifestyle, they failed to apply topical medication sufficiently. Therefore, systemic corticosteroid may be used for moderate to severe cases of senile AD with close monitoring of adverse events such as hypertension, gastric ulcer, cataract, osteoporosis, and diabetes mellitus [6].

\section{References}

1. Katsarou A, Armenaka MC (2011) Atopic dermatitis in older patients: Particular points. J Eur Acad Dermatol Venereol 25: 12-8. [Crossref]

2. Tanei R, Hasegawa Y, Sawabe M (2013) Abundant immunoglobulin E-positive cells in skin lesions support an allergic etiology of atopic dermatitis in the elderly. $J$ Eur Acad Dermatol Venereol 27:952-60. [Crossref]

3. Tanei R, Katsuoka K (2008) Clinical analyses of atopic dermatitis in the aged. The Journal of Dermatology. 2008;35:562-9. [Crossref]

4. Schmitt J, Bauer A, Meurer M (2008) Atopic eczema in adulthood. Hautarzt 59: 841852

5. Wolkewitz M, Rothenbacher D, Low M, Stegmaier C, Ziegler H, et al. (2007) Lifetime prevalence of self-report atopic diseases in a population-based sample of elderly subjects: results of the ESTHER study. Br J Dermatol 156: 693-7. [Crossref]

6. Tanei R (2009) Atopic dermatitis in the elderly. Inflammation \& Allergy-Drug Targets 8: 398-404.

7. Muto T, Hsieh SD, Sakurai Y, Yoshinaga H, Suto H, et al. (2003) Epidemiology and health services research prevalence of atopic dermatitis in Japanese adults. $\mathrm{Br} J$ Dermatol 148: 117-21.

8. Sandström Falk MH, Faergemann J (2006) Atopic dermatitis in adults: does it disappear with age? Acta Derm Venereol 86: 135-9. [Crossref] 
Bianti M (2018) Management of senile atopic dermatitis in geriatric outpatient clinic Dermatovenereology Department Cipto Mangunkusumo Hospital in 2011-2015

9. Saeki H, Tsunemi Y, Fujita H, Kagami S, Sasaki K, et al. (2006) Prevalence of atopic dermatitis determined by clinical examination in Japanese adults. J Dermatol 33: 817-9. [Crossref]
10. Infodatin Kementerian Kesehatan RI (2014) Situasi dan analisis lanjut usia Kementerian Kesehatan RI.

Copyright: $\odot 2018$ Bianti M. This is an open-access article distributed under the terms of the Creative Commons Attribution License, which permits unrestricted use, distribution, and reproduction in any medium, provided the original author and source are credited. 